\title{
Biology and role of NK cells - selected data
}

\author{
PAULINA NIEDŹWIEDZKA-RYSTWEJ ${ }^{1}$, MAŁGORZATA HERBERG ${ }^{*}$ WIESŁAW DEPTUŁA
}

${ }^{1}$ Department of Immunology, Faculty of Biology, University of Szczecin

${ }^{2}$ Department of Microbiology, Faculty of Biology, University of Szczecin

\begin{abstract}
The paper shows the characteristics of important immune cells, which are natural killer (NK) cells. Those are the cells which carry different roles in immunity, as well in physiology and diseases. Natural killer cells have a huge cytotoxical potential and are able to "kill" other types of cells. Moreover, they have cytotoxic granules and secrete many cytokines and chemokines, what improves immunity caused by NK cells. An interesting data concerning the division of NK cells' subsets have been provided, as those data evaluated over last couple of years. Nowadays, the division is made on the basis of phenotypic, functional and anatomical properties, and such subpopulations can be enumerated: CD56 dim CD16+, CD56 bright CD16-, CD56+/NKp46+ and NKT (natural killer T) cells and among uterine NK (uNK) cells, endometrial $N K(e N K)$ and decidual $N K(d N K)$ cells. Taking into account the fact that the population of NK cells is growing, their functions are also wider. There are several roles that have been studied in this paper, such as anti-infection and anti-cancer immunity, as well as their pivotal role during pregnancy.
\end{abstract}

Key words: NK cells, immunity.

(Centr Eur J Immunol 2012; 37 (4): 399-404)

\section{Introduction}

Natural killers (NK) are very important cells of the immune system, principally shaping innate immunity processes. Population of such cells in mammals constitutes from $10 \%$ to $15 \%$ of all lymphocytes present in peripheral blood, and is referred to as the third pool or lymphocytes or zero lymphocytes [1-3]. The cells were first described in 1975 in mice spleen and in human blood [4, 5]. They were defined as the cells that "spontaneously" kill cancer cells $[4,5]$. In phylogenetic development, cells similar to NK cells, the NCC (non-specific cytotoxic cells), were first recorded in fish, and are considered as precursor cells for classic NK cells [6]. Natural killer cells in mammals are large, granule cells, generated in bone marrow from common progenitor cells of lymphocytes $\mathrm{T}[2,3,7]$. According to their functions and receptor profile, as well as substances secreted, for many years NK cells were included as cytotoxic lymphocytes T, yet recently [8], the division of lymphocytes has been verified and these cells are no longer included as lymphocytes $\mathrm{T}$, but treated as a separate cell population. Natural killer cells feature receptors CD2, CD16, CD56, and differ from lymphocytes $\mathrm{T}$ by lack of re- ceptor CD3 [2]. They secrete NKCF (natural killer cytotoxic factor), as well as interferon $\gamma($ IFN- $\gamma)$, interleukin 2 (IL-2), IL-3, IL-10, granulocyte macrophage-colony stimulating factor (GM-CSF), granulocyte-colony stimulating factor (G-CSF), colony stimulating factor (CSF) and tumor necrosis factor $\alpha$ (TNF- $\alpha)$ [2, 9-14]. Natural killer cells also secrete many chemokines, including CCL2 (MCP-1), CCL3 (MIP1- $\alpha$ ), CCL-4 (MIP1- $\beta$ ), CCL5 (RANTES), XCL1 (lymphotactin), and CXCL8 (IL-8) [15]. The cells are not only characterised with the capacity of natural cytotoxicity not subjected to MHC restriction, which constitutes one of the main mechanisms of innate immunity, but also affect the acquired immunity processes $[3,15,16]$. Lately it was shown, that low-level radiation with $\mathrm{X}$ rays is a factor that may increase cytotoxicity of NK cells [17]. It was evidenced $[3,15,16,18]$ that conditioning of innate and acquired immunity by NK cells principally occurs as a result of their contact with DC-dendritic cells. These two cell types, namely NK and DC, cooperate with one another in creating effective immunological response. Their direct contact takes place i.a. in peripheral lymphoid organs, e.g. lymph nodes, which leads to activation of NK cells and maturation of DC cells. This occurs as a result of enhanced 
synthesis of factors such as IFN- $\gamma$ and TNF, and cytokines IL-2, IL-4, IL-12, IL-15 and IL-18, which have stimulating effect on maturation of antigen-presenting cells and increase cytotoxic activity of NK cells [13]. Recently, it has also been evidenced [19] that interactions between NK and DC cells are of particular importance in viral infections.

\section{Development of NK cells}

Due to their capacity of immediate response against target cells, without prior "sensitisation", NK cells have been classified as an element of innate immunity. As mentioned, the cells are generated in bone marrow, yet recent studies [20] suggest that they may also develop in the liver and in the status of physiological balance, they are located in the red splenic pulp and sinusoidal region of the liver, while during infection, they permeate near the inflammation focus, often to the white splenic pulp and parenchymatic tissue of the liver $[12,14,20]$.

Their development occurring in the bone marrow is related to NK cells' acquisition of markers CD11b and KLRG1 (killer cell lectin-like receptor subfamily G) and to the loss of receptor CD27 and TRAIL (TNF-related apoptosis-inducing ligand-ligand) [14]. Immature NK cells feature receptors inhibiting KIRs (killer immunoglobulin-like receptors) and lactin receptors LY49, the presence of which inhibit their capacity of responding, as mature NK cells have no such receptors, owing to which they are more effective in fighting inflammations, including viral infections, as well as cancer processes $[12,14]$. The development of NK cells can also be affected by other signals received by ITAM receptors (immunoreceptor tyrosine-based activatory motif), signal cascade of which for the purpose of signal transmission occurs using adapter particles, which recruit SYK (spleen tyrosine kinase) and ZAP70 (zeta-chain-associated protein kinase 70) $[12,14]$. Moreover, an important receptor for functioning of NK cells is NKp46, which is responsible for an appropriate transcription and acquired immunity [47]. After leaving the bone marrow, NK cells that have "gained" functional competencies, have the capacity to quick fighting against infection and destruction of cancer cells, as mature NK cells are present in blood and many organs, including spleen, lungs and the liver, as well as central nervous system. Their migration into the organs has not been fully recognised, yet it is known that the process is participated by many chemokines, such as CCL3, CCL4, CCL5, CCL19, CXCL12, CXCL16, CX 3 CL1 $[12,14]$. Furthermore, the migration of NK cells into organs is also related to correct expression of adhesion molecules [ $\alpha 2$ integrins, $\alpha 4$ integrins, macrophage receptor 1 (MAC1)], as well as receptors for chemokines, such as CCR1 (CCchemokine receptor 1), CCR5, CCR7, CXCR3 (CXCchemokine receptor), CXCR4, CXCR6 and $\mathrm{CX}_{3} \mathrm{CR} 1$ $\left(\mathrm{CX}_{3} \mathrm{C}\right.$-chemokine receptor), which are produced by cells characteristic of particular organs and participate in migra- tion of NK cells to such organs [12, 14]. For example, factor $\mathrm{CX}_{3} \mathrm{CL} 1\left(\mathrm{CX}_{3} \mathrm{C}\right.$-chemokine ligand 1$)$, produced by neurons, is necessary for directing $\mathrm{NK}$ cells connected with receptor $\mathrm{CX}_{3} \mathrm{CR} 1$ to the infected brain. Similarly, BrowiczKupffer cells containing CCL2, "attract" NK cells with CCR2 expression to the liver infected with MCMV virus (murine cytomegalovirus) [12, 14].

\section{Differentiation and characteristics of NK cells}

In the aspect of immunophenotype and functions performed, NK cells are not a homogenous group. Based on phenotypic, functional and anatomical properties, various subpopulations of NK cells have been recognised in humans $[9,21]$. The main factor for division of such cells is the intensity of expression of the surface adhesive molecule N-CAM (neural cell adhesion molecule), namely CD56 and particle Fc $\gamma$ RIII (CD16), as well as ligand for receptor 1 of FGFR1 (fibroblast growth factor receptor 1) [3, 13, 22]. It is also suggested that the division of such cells is also based on cytokines synthesized in response to their stimulation [13]. According to the above criteria, among peripheral blood NK cells, there are NK cells CD56 ${ }^{\text {dim CD16+, }}$ CD56 ${ }^{\text {bright }} \mathrm{CD} 16-$, CD56+/NKp46+ and NKT cells (natural killer T cell), while among them - classic, non-classic and iNKT (invariant NKT). In turn, among uterine NK cells ( $\mathrm{uNK}$ ), endometrial NK (eNK) and decidual NK (dNK) cells were identified (Table 1).

Subpopulation of NK cells showing low expression of CD56, and high expression of CD16 marker, includes cytotoxic NK cells - CD56 dim CD16+ or CD16++CD56-/+, also referred to as NK1 [1, 3, 7, 9, 13, 16, 22, 23]. The cells produce substances typical of NK cells (namely i.a. IFN- $\gamma$ and IL-2), but also IL-15, which increases their capacity for natural cytotoxicity directed against cancer cells or cells infected with bacteria, viruses and parasites. They also show expression of CXCR1 (CXC chemokine receptor 1), which probably plays a role during recruitment of NK cells to peripheral inflammation sites $[1,3,21]$. In peripheral blood, they constitute as much as $90 \%$ of all NK cells and have much shorter telomeres, due to which they are considered as more mature cells [3, 9, 21, 23]. In turn, subpopulation of

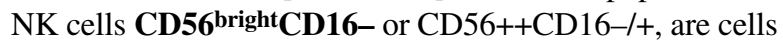
characterised with high expression of CD56 molecules, yet not featuring CD16 marker on their surface, and these are immunoregulatory NK cells, also referred to as NK2 [1, 3, $7,9,13,16,22,23]$. The cells do not produce IFN- $\gamma$, and have the capacity of producting high volumes of IL-4, IL-5 and IL-13, which is not synthesised by NK1 cells [13]. Furthermore, NK2 cells show expression of selectins L (CD62L) and receptor CCR7 for chemokines CCL19 and CCL21, which probably affects their migration to lymphoid organs. As regards NK cells - CD56+/NKp46+, it was only evidenced that they are characterised with the presence on their 
Table 1. Subpopulations, receptors and secreted substances of NK cells

\begin{tabular}{|c|c|c|}
\hline Subpopulation of NK cells & Receptors & Secreted substances \\
\hline \multicolumn{3}{|l|}{ NK cells of peripheral blood } \\
\hline $\begin{array}{l}\text { NK CD56 } 6^{\text {dim }} \text { CD16+ } \\
\text { (CD16++CD56+/-, NK cytotoxic, NK1) }\end{array}$ & CD16, CXCR1 & IFN- $\gamma$, IL-2, IL-15 \\
\hline $\begin{array}{l}\text { NK CD56 brightCD16- } \\
\text { (CD56++CD16+/-, } \\
\text { NK immunoregulatory, NK2) }\end{array}$ & CD56, selectin (CD62L), CCR7 & IL-4, IL-5, IL-13 \\
\hline CD56+/NKp46+ & CD56, Fc $\gamma$ RIIB (CD32C) & ND \\
\hline NKT classic & $\mathrm{TCR} \alpha \beta, \mathrm{CD} 161$ & IFN- $\gamma$, IL-4, IL-17A \\
\hline NKT non-classic & $\mathrm{TCR} \gamma \delta$ & IFN- $\gamma$, IL-4, IL-17A \\
\hline iNKT (inwariant) & Va14+TCR & IFN- $\gamma$, IL-4 IL-17A \\
\hline \multicolumn{3}{|l|}{ Uterine NK cells - uNK } \\
\hline eNK (endometrium NK) & like NK CD56'dimCD16+ & \\
\hline dNK (decidual NK) & like NK CD56 brightCD16- & \\
\hline
\end{tabular}

surface of the receptor inhibiting FcyRIIB (CD32C) [13]. It was evidenced [24] that the role of this small subpopulation of NK cells can be related to controlling the function and quantity of NK cells in peripheral blood, as NK cells CD56+/NKp46+ principally show inhibitory properties.

In the case of NKT cells (natural killer T cells), it is assumed that this is subpopulation of lymphocytes T featuring the properties of lymphocytes $\mathrm{T}$, as well as NK cells, constituting $0.2 \%$ of all lymphocytes $\mathrm{T}$ in peripheral blood $[2,10$, 25]. Among them, two cell groups have been differentiated: classic, featuring receptor TCR $\alpha \beta$ and CD161, and non-classic, showing expression of TCR $\gamma \delta$ and not featuring molecule CD161 on their surface [2, 26]. Natural killer T cells are characterised with the capacity to recognise glycolipid molecules presented to them by CD1d molecule, being a ligand present on macrophages and DC cells, by which they cause their activation $[2,10,25,26]$. They have antiviral, antibacterial and anti-parasite properties $[2,10,25]$. By releasing the contents of the grains or by FasL (CD95L), they are also capable of killing cancer cells [2,10, 25]. Among them, there are iNKT (invariant NKT cells), which have the regulator function in the immune system, and have both role and share in the innate and acquired immunity. They show expression of invariant receptor Va14+TCR, and, similarly as NKT cells, recognise glycolipid antigens presented by CD1d molecule. A characteristic feature of iNKT cells is their capacity, upon activation, to secrete high volumes of pro- and anti-inflammatory cytokines, which stimulate B, T, NK and DC cells [12, 14, 27].

In turn, among NK cell subpopulation within uNK cells, eNK cells and $\mathbf{d N K}$ cells were recorded. It is believed that uNK cells participate in the reconstruction of endometrial tissues, control organ functions and participate in placenta creation $[9,12,28]$. In turn, their subpopulation eNK, discovered in the uterus during the menstruation cycle, shows expression of molecules with a profile similar to NK cells CD56 ${ }^{\text {dim }}$ CD16+ in peripheral blood, and such cells participate in fighting various viral infections that may distort the menstruation cycle [9]. Another subpopulation of uNK cells includes dNK cells, with the phenotype similar to CD56 ${ }^{\text {bright }}$ CD16- cells, which, similarly as eNK, are present in the uterus during each menstruation cycle, and have receptors of natural cytotoxicity that can cause cytolysis of target cells not having major histocompatibility complex. The cells are characterised with the capacity of producing cytokines and growth factors, including angiogenesis growth factor and vascular endothelial growth factor-C (VEGF-C) [9]. It was also evidenced [28] that dNK cells are regulated by lymphocytes nTreg, as the latter produce favourable "micro-environment", which leads to production of immunoregulatory molecules that favourably affect the interaction between the mother and the foetus.

\section{The role of NK cells in infections}

Owing to cytotoxic properties, NK cells actively participate in anti-infection and anti-cancer immunity, therefore, they protect the host against viruses, bacteria, parasites, cancers, as well as actively participate in other pathological conditions (e.g. in cancer and autoimmunity) and physiological ones (e.g. pregnancy). The main importance of NK cells in immunity was recorded in viral infections, and so far, to the greatest extent, the role of such cells has been described in infections caused by influenza virus from the Orthomyxoviridae family [29], as well as HIV virus from the Retroviridae family [30], and viruses from 
the Herpes family, in particular CMV (cytomegalovirus), HSV (herpes virus) and EBV (Epstein-Barr virus), while recently by $\mathrm{HCV}$ virus (type B and C) [10-12, 32-34]. During the viral infection, usually, increased cytotoxic activity of NK cells is observed, as well as their increased blastogenesis. The activity increases, however, only after several hours from infection, and it is mainly observed in the organ infected with the virus. Natural killer cells migrate to the organ infected with the virus under the impact of locally produced chemokines, e.g. CCR7, CXCR4, CXCR1, CXCR6 [10-12, 33]. One of the methods for destroying cells infected with viruses by NK cells is the cytotoxic response, related to reduced expression of MHC molecules class I, or increased expression of MIC (macrophage inflammatory proteins) or ULBP (UL16 binding protein 4 or NKG2D ligand 4) in target cells. The reduced quantity of major histocompatibility complex MHC class I in target cells infected with a virus makes them more susceptible to cytotoxicity of NK cells, as well as by the increased volume of cytokines secreted by them, in particular IFN- $\alpha$ and IFN- $\gamma$. The last substance not only inhibits viral replication in the infected cells, but also stimulates production of nitrogen oxide synthase by macrophages $[10-12,14]$. An important role in the mechanism of fighting cells infected with a virus by NK cells is played by the apoptosis process [34-36]. Natural killer cells induce this process by secretion of TNF and secretion of perforin and granzymes, as well as ligation of Fas receptor [34-36]. Natural killer cells also play an important role in viral hepatitis type B and C. It must be noticed that immunological mechanism in the liver are very important for correct functioning of the entire organism, as liver is the organ that participates in the metabolism of the macroorganism [36]. An important role in supervision over immunocompetence of the liver also belongs to BrowiczKupffer cells, dendritic cells, mastocytes, granulocytes and lymphocytes $\mathrm{T}$ and $\mathrm{B}$ and their subpopulations, as well as NKT cells [36]. And so, in the case of NK cells in the liver, which are located in sinusoids of this organ, as well as are often adjacent to endothelial cells, they constitute an important element of liver immunity. Furthermore, they constitute from $30 \%$ to $50 \%$ of liver lymphocytes, although during an illness the volume may increase to $90 \%$ [19]. Natural killer cells in the liver are smaller and are characterised with lower density and smaller granules as compared to NK cells in peripheral blood, and produce lower volume of IFN- $\gamma$ [19]. It was evidenced that NK cells in the liver also have immunological memory, which proves they are even more universal than believed so far [12]. Memory NK cells in the liver show expression of CXCR6 - receptor for chemokine CXCL16 produced by endothelium of liver sinusoids, and their antiviral action much depends on the activity of IFN- $\alpha$ [12]. During the infection with HCV, stimulated with IFN- $\alpha$, NK cells destroy liver cells infected with the virus in a path dependent on TRAIL [12]. Furthermore, a very interesting aspect of the role of NK cells in hepatitis type $\mathrm{C}(\mathrm{HCV})$, is the homology of receptors KIR and molecules HLA-C [19]. It was evidenced [30] that during the infection with $\mathrm{HCV}$, there is an increase in the volume of NK cells CD56 $6^{\text {bright }}$ CD16- and decrease in the volume of NK cells CD56 dim CD16+. Furthermore, it was recorded [19] that an important role in the infection belongs to IFN- $\gamma 3$ (IFN type III IL-28), which is a specific mediator for the course of the infection, and it is this factor that effectively "clears" hepatocytes of the virus.

Natural killer cells also have their role in fighting bacterial and parasite infections, although there is less data than in the case of viral infections. It is, however, known that during lung infection caused by Staphylococcus aureus, there is intensive inflow of NK cells to the bronchoalveolar space, and their production of increased volumes of TNF [12]. In turn, NK cell role in fighting parasite infections, e.g. with Toxoplasma gondii, Plasmodium falciparum, Leishmania major is rather through production of cytokines than by their cytolytic activity. It was evidenced that NK cells stimulated by IL-12, produced by stimulated macrophage or dendritic cells, produce IFN- $\gamma$ and TNF- $\alpha$, by which they activate phagocyting cells, which as a consequence leads to parasite destruction [11]. Moreover, there have been data showing, that NK cells participate in such diseases as otitis media with effusion, as a noticeable increase of the number of NK cells has been recorded during this infection [31].

Natural killer cells also participate in organism protection against the development of tumour disease, as they spontaneously kill tumour cells, at the same time saving normal, healthy cells. One of the reasons for such selective killing is the rather high expression of molecules activating NK cells on the surface of tumour cells as compared to normal cells. Natural killer cells act in the early phases of cancerogenesis, destroying cells with damaged DNA and show increased expression of molecules activating NK cells, namely MICA and MICB [10, 37]. Activation and sensitisation of NK cells is also caused by the lack or reduced expression of MHC class I on the surface of tumour cells [10, 13, 20]. Hence it is suspected that two properties are responsible for their sensitivity against tumour cells, namely increased number of ligands for receptors activating natural killer cells, and reduced expression of inhibiting ligands of MHC class I [20, 37]. It was evidenced that NK cells show the greatest cytolitic activity against tumour cells during their mitosis and, furthermore, it was determined that their activation depends on the action of IL-12, IL-15, IL-19 and IL-28, secreted by the activated macrophages [3]. The activated NK cells become "aggressive" and begin the search for target cells. After recognising them, they "adhere" to the membrane of tumour cells, after which they "inject" them with substances leading to lysis of the cells attacked. Their activity without the need to coat target cells with immunoglobulines, causes that the cells can destroy tumours in the very early phases of development $[38,39]$. Destruction of one 
tumour cell lasts not more than five minutes, after which NK cell attacks the next "victim". It was evidenced that one NK cell during its life may destroy even twenty-seven tumour cells [38]. It was also determined [40] that in anti-cancer defence, the role of NK cells is regulated i.a. by regulator lymphocytes $\mathrm{T}_{\text {reg }}$, which are in charge of controlling correct proliferation of NK cells. Recently [41], it has also been pointed to the indirect participation of platelets in regulating the function of NK cells in anti-cancer defence. It was evidenced [41] that thrombocytes, by expression of such immunoregulatory molecules on their surface as CD40 and CD40L, can impact on the function of NK cells.

It was also pointed that NK cells participate in autoimmunity, as in allogenic transplantations, the cells participate in effector phase of the reaction of acute transplant rejection $[10,42]$. Their role comprises leading to cytolysis of cells in target tissues, via two mechanisms: releasing the contents of cytolytic granules and activation of Fas receptors $[10,43]$. Natural killer cells are the first cells that appear in hosts as early as 1-3 months from transplantation [44]. In the case of xenogenic transplantations, NK cells destroy cells in target tissues, using the mechanism of antibodydependent cytotoxicity and, similarly as in the case of allogenic transplants, by compounds contained in cytolytic granules and interaction Fas/Fas ligand [42]. Natural antibodies present in the serum, specific for hydrocarbon epitopes, containing as the final molecule $\operatorname{Gal}(\alpha 1,3) \mathrm{Gal}$ (galactose- $\alpha$ 1,3 -galactose) present in glycoproteins and glycolipids of animal endothelium, constitute the main barrier for xenotransplant incompatibility. It was evidenced that NK cells directly recognise $\mathrm{Gal}(\alpha 1,3) \mathrm{Gal}$ during adhesion to animal endothelial cells, owing to which their activation occurs. Furthermore, recognition of epitopes of $\operatorname{Gal}(\alpha 1,3) \mathrm{Gal}$ may occur via the aforementioned natural antibodies anti-Gal, which bind to receptor Fc $\gamma$ RIII present at NK cells [10, 42]. The studies evidenced [45] that NK cells are also of importance in autoimmunity disorders, such as psoriasis. It was evidenced [45] that their number significantly grows in patients with the symptoms of the disease, as both the share of the cells increases in peripheral blood, and their increased number occurs in places with lesions.

Natural killer cells have an important role during pregnancy, as they indicate passivity, owing to which the mother's immune system tolerates the foetus developing in the uterus. In physiological conditions, uterus NK cells, both eNK and dNK, are not aggressive to foetal tissues [27]. During the ninth day of the menstruation cycle, in the proliferation phase that precedes ovulation, the uterine mucosa (endometrium) begins to reconstruct, and becomes richly vasculated, and significant volumes of NK cells appear there. On the fourteenth day of the cycle, in the secretion phase, uterine NK cells begin to proliferate, after which they differentiate. During this phase in the uterus, there may be implantation of the foetus. If this does not happen, however, uNK cells die, and then are removed from the organism together with endometrium during menstruation. If the implantation takes place, their number suddenly grows at the border between the foetus and the mother, where they cooperate with the cells of the foetal trophoblast, owing to which they engage in placenta formation [46]. The cooperation is possible owing to the presence on the trophoblast surface of MHC such as HLA-C, HLA-G and HLA-E. All such molecules can be recognised both by inhibiting and activating receptors of uterine NK cells, which probably stimulates them to production of many cytokines and growth factors $[12,46]$. Among uNK cells, the greatest capacity for production of such compounds is observed for dNK cells that produce i.a. angiogenesis growth factor and VEGF-C, which affect migration and proliferation of endothelial cells, thus supporting angiogenesis, which is an important condition for successful pregnancy. Furthermore, the compounds modify mother arteries supplying the growing foetus with the necessary blood, nutrients and oxygen [9]. In a situation where decidual macrophages or dendritic cells recognise trophoblast, uNK cells may become active and obtain cytotoxic functions, similar to peripheral NK cell functions [9]. As a result, in the endometrium, there is reduction to cytotoxicity of uNK cells with low cytotoxicity, namely dNK, and activity of cytotoxic uNK cells, namely eNK, grows. This phenomenon was observed in women that miscarried many times. Endometrial NK cells reveal much greater activities in them than in women who had correct course of the pregnancy [9]. The latest data evidence that inhibiting receptors of NK cells, by interaction with HLA-G, present on the cells of foetal trophoblast, may lead to inhibition of their cytotoxicity in reference to the foetus [11]. Therefore, a hypothesis was made that self-occurring miscarriages may be caused by insufficient inhibition of cytotoxicity of uNK cells [9].

\section{Conclusions}

As confirmed by many data in the literature, NK cells are rightly referred to as the third pool of lymphocytes, as they have a range of functions, principally in innate immunity. Their role was confirmed in viral, bacterial and parasite infections and in the course of tumour diseases. The function of the cell was also described in autoimmunity, while particular importance must be given to the role of the cells during pregnancy, which is caused by the presence of specific subpopulations of such cells in the uterus, which make the function of NK cells in the condition of pregnancy deserve special attention.

\section{References}

1. Cooper MA, Fehniger TA, Turner SC, et al. (2001): Human natural killer cells: a unique innate immunoregulatory role for the CD56 bright subset. Blood 97: 3146-3151.

2. Deptuła W, Tokarz-Deptuła B, Stosik M (2008): Immunology for biologists. US, Szczecin. 
3. Kopeć-Szlęzak J, Podstawka U (2007): Biologia komórek NK (Natural Killer). Onkol Pol 10: 115-119.

4. Volz A, Radeloff B (2006): Detecting the unusual: natural killer cells. Prog Nucleic Acid Res Mol Biol 81: 473-541.

5. Sentman CL, Barber MA, Barber A, Zhang T (2006): NK cell receptors as tools in cancer immunotherapy. Adv Cancer Res 95: 249-292.

6. Roman A (1991): Komórki NK - charakterystyka i rola w organizmie. Wszechświat 92: 117-120.

7. Biedroń M, Mazur G, Wróbel T, Kuliczkowski K (2003): Receptory komórek NK. Adv Clin Exp Med 12: 529-535.

8. Niedźwiedzka-Rystwej P, Deptuła W (2012): Charakterystyka limfocytów T. Post Hig Med Dosw (w druku).

9. Bielawska-Pohl A, Duś D (2009): When killers become helpers - the ambivalent role of NK cells. Adv Clin Exp Med 18: 537-542.

10. Gołąb J, Jakóbisiak M, Lasek W, Stokłosa T (2008): Immunologia. Wydawnictwo Naukowe PWN, Warszawa.

11. Nakamura MC (1997): Natural killer cells in immune regulation. Clin Immunol 17: 151-154.

12. Shi FD, Ljunggren HG, La Cava A, Van Kaer L (2011): Organspecific features of natural killer cells. Nat Rev Immunol 11: 658-671.

13. Sochocka M (2008): Rozpoznawanie patogenów przez wrodzony system odporności. Post Hig Med Dosw 62: 676-689.

14. Sun JC, Lanier LL (2011): NK cell development, homeostasis and function: parallels with CD8+ T cells. Nat Rev Immunol 11: 645-657.

15. Vivier E, Raulet DH, Moretta A, et al. (2011): Innate or adaptive immunity? The example of natural killer cells. Science 331: 44-49.

16. Sochocka M, Błach-Olszewska Z (2005): Mechanizmy wrodzonej odporności. Post Hig Med Dosw 59: 250-258.

17. Nowosielska EM, Wrembel-Wargocka J, Cheda A, Janiak MK (2006): A single low-dose irradiation with $\mathrm{X}$-rays stimulates NK cells and macrophages to release related to cytotoxic functions of these cells. Centr Eur J Immunol 31: 51-56.

18. Kaczmarczyk M, Niedźwiedzka P, Deptuła W (2006): Charakterystyka komórek dendrytycznych. Adv Clin Exp Med 15: 575-580.

19. Cooper MA, Fehniger TA, Fuchs A, et al. (2004): NK cell and DC interactions. Trends Immunol 25: 47-52.

20. Zeromski J, Mozer-Lisewska I, Kaczmarek M, et al. (2011): NK cells prevalence, subsets and function in viral hepatitis C. Arch Immunol Ther Exp (Warsz) 59: 449-455.

21. Vivier E, Tomasello E, Baratin M, et al. (2008): Functions of natural killer cells. Nat Immunol 9: 503-510.

22. Carson W, Caligiuri M (1996): Natural killer cell subsets and development. Methods 9: 327-343.

23. Vivier E (2006): What is natural in natural killer cells? Immunol Lett 107: 1-7.

24. Dutertre CA, Bonnin-Gélizé E, Pulford K, et al. (2008): A novel subset of NK cells expressing high levels of inhibitory Fc $\gamma$ RIIB modulating antibody-dependent function. J Leukoc Biol 84: 1511-1520.

25. Johansson S, Berg L, Hall H, Höglund P (2005): NK cells: elusive players in autoimmunity. Trends Immunol 26: 613-618.

26. Kopeć-Szlęzak J (2005): Subpopulacje limfocytów T. Onkol Pol 8: 17-20.

27. Cerundolo V, Kronenberg M (2010): The role of invariant NKT cells at the interface of innate and adaptive immunity. Semin Immunol 22: 59-60.
28. Vacca P, Moretta L, Moretta A, Mingari MC (2011): Origin, phenotype and function of human natural killer cells in pregnancy. Trends Immunol 32: 517-523.

29. Mao H, Tu W, Qin G, et al. (2009): Influenza virus directly infects human natural killer cells and induces apoptosis. J Virol 83: 9215-9222.

30. Śliwa-Dominiak J, Tokarz-Deptuła B, Deptuła W (2012): Makroorganizm a wirusy - wybrane dane. Post Mikrobiol (w druku).

31. Wojdas A, Stankiewicz W, Zielnik-Jurkiewicz B, et al. (2011): Early and late activation markers on thymus-dependent lymphocytes and natural killer cells in the blood of childreb with adenoid hypertrophy and concomitant otitis media with effusion. Centr Eur J Immunol 36: 262-266.

32. Hamerman JA, Ogasawara K, Lanier LL (2005): NK cells in innate immunity. Curr Opin Immunol 17: 29-35.

33. Vivier E, Tomasello E, Baratin M, et al. (2008): Functions of natural killer cells. Nat Immunol 9: 503-510.

34. Brandstadter JD, Yang Y (2011): Natural killer cell responses to viral infection. J Innate Immun 3: 274-279.

35. Groth A, Klöss S, von Strandmann EP, et al. (2011): Mechanisms of tumor and viral immune escape from natural killer cell-mediated surveillance. J Innate Immun 3: 344-354.

36. Trzeciak-Ryczek A, Tokarz-Deptuła B, Deptuła W (2011): Immunity of the liver - selected data. Centr Eur J Immunol 36: 193-196.

37. Höglund P, Klein E (2006): Natural killer cells in cancer. Semin Cancer Biol 16: 331-332.

38. Moretta L (2007): NK cell-mediated immune response against cancer. Surg Oncol 16: S3-5.

39. Kurkowski MK, Bobek-Billewicz B (2003): Zaburzenia snu a schorzenia nowotworowe. Sen 3: 87-94.

40. Stojanovic A, Cerwenka A (2011): Natural killer cells and solid tumors. J Innate Immun 3: 355-364.

41. Placke T, Kopp HG, Salih HR (2011): Modulation of natural killer cell anti-tumor reactivity by platelets. J Innate Immun 3: 374-382.

42. Maślińska D (1999): Programowana śmierć komórki (apoptoza) w procesie zapalnym. Nowa Medycyna - Reumatologia 12: 34-41.

43. Piątkowska-Jakubas B, Krawczyk J, Skotnicki AB (2004): Nowe aspekty immunologiczne ostrej reakcji przeszczep przeciwko biorcy po allogenicznej transplantacji szpiku kostnego. Adv Clin Exp Med 13: 1003-1011.

44. Kacińska E, Goździk J, Czajka H (2008): Dlaczego trzeba szczepić pacjentów po przeszczepach komórek krwiotwórczych? Przegl Lek 2: 87-91.

45. Tobin AM, Lynch L, Kirby B, O'Farrelly C (2011): Natural killer cells in psoriasis. J Innate Immun 3: 403-410.

46. Parham P (2004): NK cells and trophoblasts: partners in pregnancy. J Exp Med 200: 951-955.

47. Narni-Mancinelli E, Jaeger BN, Bernat C, et al. (2012): Tuning of natural killer cell reactivity by NKp46 and Helios calibrates T cell responses. Science 335: 344-348. 